\title{
Mechanisms Maintaining Southern Ocean Meridional Heat Transport under Projected Wind Forcing
}

\author{
PAUL SPENCE \\ Climate Change Research Centre, University of New South Wales, Sydney, Australia \\ Oleg A. SAenKo \\ Canadian Centre for Climate Modelling and Analysis, Environment Canada, Victoria, British \\ Columbia, Canada \\ CARolina O. Dufour \\ Laboratoire des Ecoulements Géophysiques et Industriels, CNRS/Université de Grenoble, Grenoble, and \\ Laboratoire des Sciences du Climat et l'Environnement, CEA/CNRS/UVSQ/IPSL, Paris, France \\ JULIEN LE SOMMER \\ Laboratoire des Ecoulements Géophysiques et Industriels, CNRS/Université de Grenoble, \\ Grenoble, France \\ MATTHEW H. ENGLAND \\ Climate Change Research Centre, University of New South Wales, Sydney, Australia
}

(Manuscript received 2 January 2012, in final form 28 May 2012)

\begin{abstract}
Meridional heat transport (MHT) in the Southern Ocean (SO) and its components are analyzed with two eddy-permitting climate models. The two models present a consistent picture of the MHT response to projected twenty-first-century changes in SO winds. In agreement with a recent analysis based on an ocean data synthesis product, much of the MHT in the SO is found to be due to the time-mean fields of meridional velocity and temperature. The change in the net MHT tends to be small relative to the interannual variability at most SO latitudes. However, both models exhibit significant changes at most latitudes south of $30^{\circ} \mathrm{S}$ in individual components of MHT. A simple framework wherein changes in the eddy and mean heat transports tend to compensate each other is not supported by the authors' results. Instead, the MHT response is composed of sizeable contributions from essentially all of the MHT components, with the eddy and mean heat transports often having the same sign.
\end{abstract}

\section{Introduction}

Observational estimates suggest that outside of low latitudes most of the meridional heat transport (MHT) in the climate system is carried within the atmosphere (e.g., Trenberth and Caron 2001). In spite of its relative size, oceanic heat transport and its change can have a

Corresponding author address: Paul Spence, Climate Change Research Centre, Level 4, Mathews Building, University of New South Wales, Sydney, NSW 2052, Australia.

E-mail: paul.spence@unsw.edu.au profound influence on climate (Saenko 2009). In the Southern Hemisphere, where the strong Antarctic Circumpolar Current (ACC) tends to isolate the Southern Ocean (SO) from tropical heat sources, most of the oceanic poleward heat transport is thought to be due to the mesoscale eddy field (e.g., de Szoeke and Levine 1981). This view, however, applies only to cross-stream heat transport: that is, the heat transport across a particular front or across the mean position of the ACC. In contrast, our focus here is on meridional heat transport, which is likely to have a strong contribution from mean currents (Volkov et al. 2010; Meijers et al. 2007). This is 
because the mean flow of the ACC is not strictly zonal. It carries warm waters from the region south of the Agulhas Retroflection to the higher latitudes of the Drake Passage; subsequently, the Malvinas Current carries cold waters northward. Using an ocean data synthesis product, Volkov et al. (2010) estimate the MHT due to this gyre-like circulation pattern to be on the order of $1 \mathrm{PW}\left(=10^{15} \mathrm{~W}\right)$ between $45^{\circ}$ and $50^{\circ} \mathrm{S}$. Because SO heat transport is a poorly observed quantity, here we use two distinct high-resolution models to independently examine this result.

However, the main goal of the study is to understand changes in SO heat transport in response to projected wind stress changes, a topic not addressed by Volkov et al. (2010). Here, we investigate how the MHT and its components respond to the projected twenty-firstcentury poleward intensification of SO wind stress (Fyfe et al. 2007), identified as a shift in the southern annular mode (SAM) toward a higher index state. To date, existing studies have focused primarily on the role of the SO transient processes: namely, mesoscale eddies (e.g., Farneti and Delworth 2010). A picture that has emerged from these studies is that changes in the eddy and mean heat transports tend to compensate each other, with mesoscale-resolving ocean models demonstrating that an enhanced eddy heat flux can offset the cooling induced by changes in Ekman pumping (e.g., Hogg et al. 2008). However, mesoscale-resolving models are generally unable to evaluate the response of the intermediate and deep ocean to changing wind stress because of either 1) relatively short integration periods, 2) nonglobal spatial domains, 3) specified surface buoyancy fluxes, or 4) idealized physics. Here, we analyze changes in the total MHT in the SO and its components with two distinct ocean eddy-permitting models: the University of Victoria Earth System Climate Model (ESCM) and the Nucleus for European Modelling of the Ocean (NEMO) modeling framework (Madec 2008) as implemented in the PERIANT025 regional model configuration of the Drakkar consortium (Drakkar Group 2007). The ESCM is an unconstrained global coupled climate model of intermediate complexity, while PERIANT025 is an uncoupled SO model forced at the northern boundary with output from a global ocean model. Taken together, results from these model simulations suggest a more complex SO heat transport response to the projected changes in the subpolar westerly winds than suggested by the eddy heat fluxes in idealized models (e.g., Hogg et al. 2008).

\section{Models, experimental design, and methods}

The following subsections outline key features of the model simulations and the methodology employed to evaluate the SO MHT and its components.

\section{a. ESCM}

The ESCM is described in detail in Weaver et al. (2001). It couples a vertically integrated energy-moisture balance atmospheric model, a thermodynamic/dynamic sea ice model, and a land surface model with the Geophysical Fluid Dynamics Laboratory Modular Ocean Model (Pacanowski 1995). Here, the oceanic component adopts an eddy-permitting horizontal resolution of $0.2^{\circ} \times 0.4^{\circ}$ (latitude $\times$ longitude) and 19 vertical levels The model parameters and spinup procedure are described in Spence et al. (2010). The model was equilibrated for about $100 \mathrm{yr}$, starting from a long-term spinup of a $1.8^{\circ} \times 3.6^{\circ}$ model version. This allows us to evaluate deep-ocean flows in a near-equilibrium state of a coupled global climate model without idealized buoyancy fluxes or boundary conditions.

Two ESCM simulations are analyzed: a control simulation (ESCM_CNTRL) and a wind perturbation simulation (ESCM_SAM). These simulations are discussed in detail in Spence et al. (2010), where the corresponding model runs are labeled as the "lower viscosity" simulations. In the ESCM_CNTRL, the wind stress corresponds to the National Centers for Environmental Prediction-National Center for Atmospheric Research (NCEP-NCAR; Kistler et al. 2001) reanalysis climatology. The ESCM_SAM simulation is identical to the ESCM_CNTRL, except that poleward-intensifying wind anomalies projected for the years 2061-2100 have been added to the ESCM_CNTRL wind stress in the SO (Fig. 1a). The wind anomalies have been assembled from simulations performed by 10 different global climate models that were forced by the same $\mathrm{CO}_{2}$ trajectory over the twenty-first century (see Fyfe et al. 2007).

\section{b. NEMO in the regional configuration PERIANT025}

The modeling system NEMO couples the hydrostatic, primitive equation ocean model Océan Parallélisé (OPA) with the Louvain-la-Neuve (LIM) sea ice model. Here, we use a model configuration (PERIANT025) implemented by the Drakkar Group (Drakkar Group 2007). PERIANT025 is a regional extraction from the global $1 / 4^{\circ}$ ORCA025 configuration, which includes all oceans south of $30^{\circ} \mathrm{S}$. The horizontal resolution varies with the cosine of the latitude such that the grid size is about $14 \mathrm{~km}$ at $60^{\circ} \mathrm{S}$. The vertical grid is a $z$ grid with 46 vertical levels. The control state atmospheric forcing is the Drakkar Forcing Set 3 (DFS3; Brodeau et al. 2010), which is derived from a combination of reanalysis [40-yr European Centre for Medium-Range Weather Forecasts (ECMWF) Re-Analysis (ERA-40); Uppala et al. 
a)

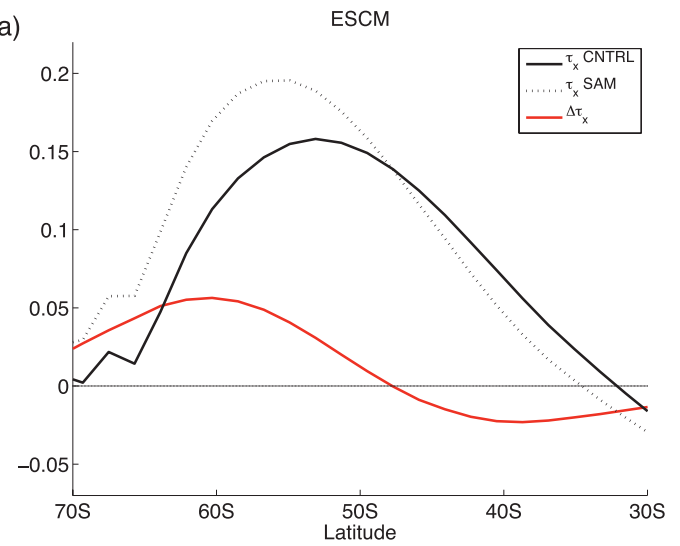

b)

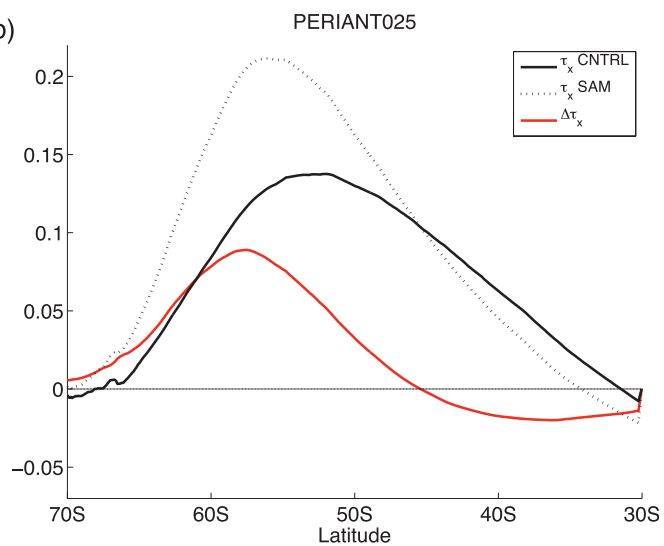

FIG. 1. SO wind stress (Pa) in the control runs (solid black) and at the end of the SAM wind forcing runs (dashed). Also shown are the corresponding anomalies in wind stress (red; $\Delta \tau_{x} ; \mathrm{m} \mathrm{s}^{-1} \times 10^{-5}$ ). (left) Note that the ESCM simulation is forced with the monthly SO wind stress anomalies projected for the years 2061-2100 by Fyfe et al. (2007). (right) The PERIANT025 model configuration SAM forcing is held constant for a 25 -yr period.

2005] and observational data. The northern boundary at $30^{\circ} \mathrm{S}$ is open and forced with output from the Drakkar global ORCA025-G70 simulation (Barnier et al. 2006). A 3D relaxation of Antarctic Bottom Water toward climatology is used. More details on the model configuration design and spinup procedure can be found in Dufour et al. (2012).

Two PERIANT025 simulations are analyzed: a control (PER_CNTRL) and a wind perturbation (PER SAM) simulation. PER_CNTRL is integrated from 1980 to 2004 with the DFS3 control state atmospheric forcing. The PER_SAM simulation is identical to PER_CNTRL, except that the spatial surface wind anomaly pattern of the SAM is added to the control state winds with a magnitude of plus two standard deviations of the SAM index (see Fig. 1b). These PERIANT025 simulations are discussed in detail in Dufour et al. (2012), where the corresponding control and SAM forcing model runs are labeled as the "REF025" and "SAM025+++" simulations.

\section{c. Meridional heat transport decomposition}

Following Bryan (1982) and adopting the notation of Volkov et al. (2010), the net MHT $\bar{Q}(y)$ can be decomposed as follows:

$\bar{Q}(y)=\iint \rho C_{p}\left\{[\bar{V}][\bar{\theta}]+\overline{\left[V^{\prime}\right]\left[\theta^{\prime}\right]}+(\bar{V})(\bar{\theta})+\overline{\left(V^{\prime}\right)\left(\theta^{\prime}\right)}\right\} d z d x$,

where $\rho$ is the potential density of seawater, $C_{p}$ is the specific heat capacity of seawater at constant pressure, $V(x, y, z, t)$ is the meridional velocity, and $\theta(x, y, z, t)$ is potential temperature. The overbar indicates averaging in time, whereas the prime represents the deviation from the corresponding time-mean field; [.] denotes zonal averaging, whereas $(\cdot)$ represents the deviation from the zonal average. The four terms on the right-hand side of Eq. (1) are due to 1) the time-mean overturning circulation, 2) the transient overturning circulation, 3) the time-mean horizontal (or "gyre") circulation, and 4) the transient horizontal (gyre) circulation. Alternatively, the third and fourth terms on the right-hand side of Eq. (1) can be considered the "mean standing eddy" and the "transient standing eddy" contributions to the MHT, respectively.

In these calculations, $V$ and $\theta$ are represented at 5-day intervals over a 5 -yr period by instantaneous snapshots in the ESCM (i.e., their value at a specific model time step without time averaging) and by time averages in PERIANT025. An evaluation of the sensitivity of the MHT calculations to the use of snapshot versus timeaverage data revealed little difference. Note that Eq. (1) ignores the MHT contribution by lateral diffusion, a possibly sizeable term (Treguier et al. 2007) that is difficult to quantify in postprocessing mode. The ESCM CNTRL and PER_CNTRL MHT estimate is calculated over the last $5 \mathrm{yr}$ of the control state simulations. Model drift is accounted for, at least in a linear sense, in the forcing response by differencing the SAM-forced simulations from concomitantly extended control state simulations. SAM anomalies are determined by differencing the last 5 yr of ESCM_SAM and PER_SAM runs from the last $5 \mathrm{yr}$ of their respective control state runs. Estimates of the standard deviation of MHT interannual variability are determined from the $10 \mathrm{yr}$ of timeinterval data available for each model (i.e., data taken at 5-day intervals over the last $5 \mathrm{yr}$ of both the control 
and SAM simulations). Using data from both the control and SAM simulations to determine the range of interannual variability in each model assumes that the interannual variability range is not significantly affected by the SAM forcing.

\section{d. Model evaluations}

The 5-yr-mean ACC transport through Drake Passage at the end of the ESCM_CNTRL simulation is $152 \mathrm{~Sv}\left(1 \mathrm{~Sv} \equiv 10^{6} \mathrm{~m}^{3} \mathrm{~s}^{-1}\right)$, which is within the $153 \pm$ $5 \mathrm{~Sv}$ observational-based state estimate of Mazloff et al. (2010). The PER_CNTRL simulation has a 1995-2004 average Drake Passage transport of 144 Sv. Details on the ACC response to the wind forcing in the ESCM and PERIANT025 can be found in Spence et al. (2010) and Dufour et al. (2012), respectively. Here, we simply note that the transport through Drake Passage in the ESCM_SAM simulation increases by 9 Sv over the first decade of the wind forcing and then stabilizes, while the mean ACC position has migrated poleward by $1.85^{\circ}$ after the 40-yr forcing period. In comparison, when the ESCM is run with a higher horizontal ocean viscosity, thereby suppressing mesoscale activity, there is a $22-\mathrm{Sv}$ increase in ACC transport. In the PER_SAM simulation, the 1995-2004 average Drake Passage transport is increased by $10 \mathrm{~Sv}$ and the ACC has migrated poleward by $0.3^{\circ}$.

While the ESCM and PERIANT025 simulations discussed in this study offer a unique opportunity to evaluate the mechanisms of SO MHT, differences between the model simulations is an important element of uncertainty to be considered when interpreting the results. The following lists some key differences between the two models and their respective forcings: (i) The PERIANT025 model configuration has more than double the vertical resolution of the ESCM and a slightly higher horizontal resolution. (ii) The specified atmospheric state used for model forcing, restoring AABW conditions, and superficial boundary at $30^{\circ} \mathrm{S}$ in PERIANT025 may act to inhibit the model response to the wind forcing. (iii) The ESCM_SAM simulation undergoes $15 \mathrm{yr}$ more of wind forcing than the PER_SAM simulation. (iv) The pattern of the SAM forcing is not the same between the two models (see Fig. 1). In particular, note that the PER SAM simulation is subject to a larger amplitude of wind stress anomaly than the ESCM_SAM but a slightly smaller poleward shift in wind stress position.

We now evaluate the ability of both models to reasonably simulate the net SO MHT. Figure 2 shows the net SO MHT produced in the ESCM_CNTRL and PER_CNTRL simulations, along with those implied by the NCEP-NCAR (Kistler et al. 2001) and ECMWF (ERA-40; Uppala et al. 2005) reanalysis products. The

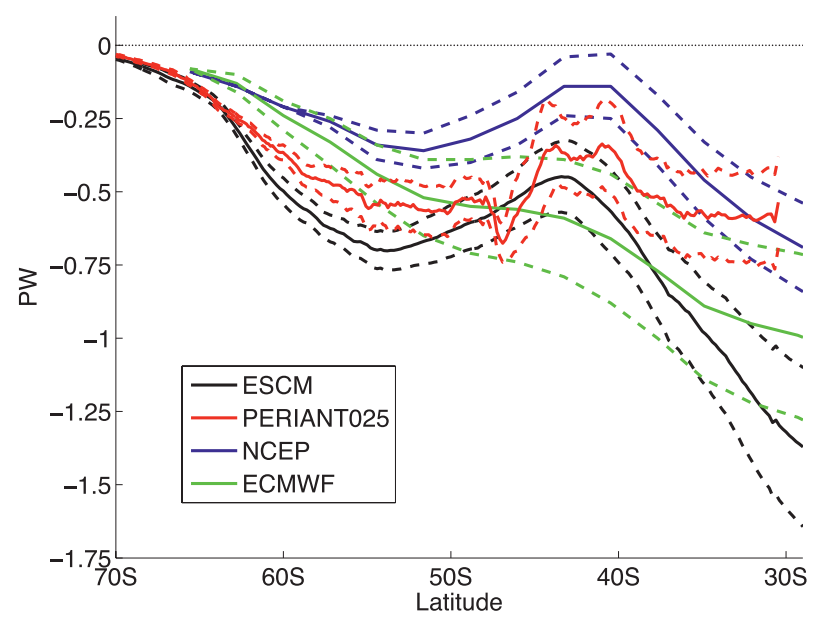

FIG. 2. Solid lines represent the total SO MHT in the ESCM and PERIANT025 control state simulations, along with heat transports implied by surface heat fluxes in the NCEP-NCAR and ECMWF reanalysis products (Trenberth and Caron 2001). The dashed lines represent a one standard deviation range of interannual variability for each MHT estimate.

MHT estimates from the reanalysis products were determined by Fasullo and Trenberth (2008) from surface heat fluxes. The discrepancy between the MHT of the two reanalysis products illustrates the large uncertainty in the available estimates for the SO surface heat fluxes. We also note that an estimate of the MHT based on surface heat fluxes assumes an equilibrated climate state with steady ocean heat content.

Both the ESCM_CNTRL and PER_CNTRL simulations reproduce reasonably well the structure of MHT derived from the reanalysis products. We note that none of the MHT estimates in Fig. 2 has an interannual variability range that is consistently (i.e., at all SO latitudes) within the interannual variability range of another estimate. For example, the two reanalysis products do not have an overlapping interannual variability range of MHT between roughly $32^{\circ}$ and $48^{\circ} \mathrm{S}$. We also note that both the PERIANT025 and ESCM transports are within the range of other observational MHT estimates at all latitudes (see Fig. 5 of Ganachaud and Wunsch 2003).

The resolution of both the ESCM and PERIANT025 simulations captures transient and stationary mesoscale features at scales larger than the baroclinic Rossby radius, which are prominent in the SO along the path of the ACC (Stammer 1997). Still, the ocean eddy kinetic energy (EKE) of these simulations is underestimated compared to satellite altimetry estimates (Fig. 3). (Note that the ESCM and PERIANT025 EKE are derived from the surface velocity field.) It is expected that eddypermitting models will underestimate EKE, since, using available potential energy (APE), EKE/APE $\approx R^{2} / L^{2}$ 


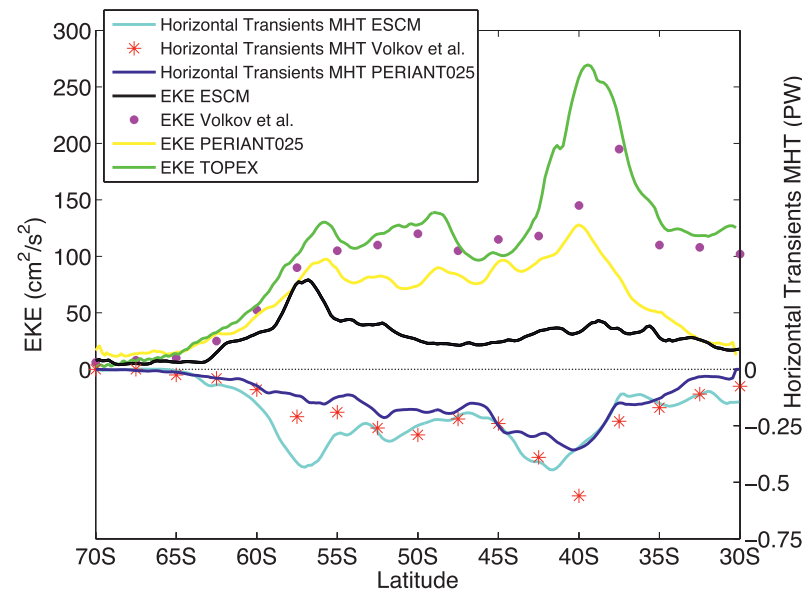

FIG. 3. On the left axis are zonally averaged near-surface EKE in the ESCM_CNTRL (black) and PER_CNTRL (yellow) runs and estimates from the ocean data synthesis product of Volkov et al. (2010) (magenta) and from TOPEX/Poseidon satellite altimetry (green; Ducet et al. 2000). On the right axis are zonally averaged and vertically integrated SO transient MHT by the horizontal circulation for the ESCM_CNTRL (cyan) and PER_CNTRL (blue) run and estimates from the ocean data synthesis product of Volkov et al. (2010) (red).

(Gill 1982), where $R$ is baroclinic Rossby radius and $L$ is the characteristic eddy scale. For flows with $L>R$, most of the energy is confined into potential form. Hence, it is not uncommon for eddy-permitting models with comparable resolution to underestimate EKE (Jayne and Marotzke 2002). This is a necessary sacrifice when it comes to multidecadal simulations. The largest contributions to the EKE in both models are found in the Agulhas retroflection $\left(40^{\circ} \mathrm{S}\right)$ and near topographic features in the North Scotia Ridge $\left(55^{\circ}-60^{\circ} \mathrm{S}\right)$, the Crozet and Kerguelen Plateaus $\left(48^{\circ}-55^{\circ} \mathrm{S}\right)$, and the Campbell Plateau $\left(55^{\circ} \mathrm{S}\right)$.

However, even though the simulations underestimate the EKE, the SO eddy heat transport generated by the horizontal circulation is reasonably close to the ocean data synthesis estimate of Volkov et al. (2010) (Fig. 3). It is also close to the net SO eddy heat transport simulated by other eddy permitting models (e.g., Jayne and Marotzke 2002; Meijers et al. 2007). Note that the eddy MHT associated with overturning circulation is found to be very small (i.e., $<0.05$ PW; see section 3a and Figs. 5a,b) in PERIANT025, the ESCM, and the ocean data synthesis estimate of Volkov et al. (2010). Estimates of the eddy heat transport across streamlines of the ACC are in the range of 0.3-0.9 PW (Gille 2003), but purely observational estimates of SO eddy MHT are currently unavailable. The SO EKE of the Volkov et al. (2010) ocean data synthesis product is near the satellite altimetry estimate (Fig. 3). This implies that the eddies not resolved

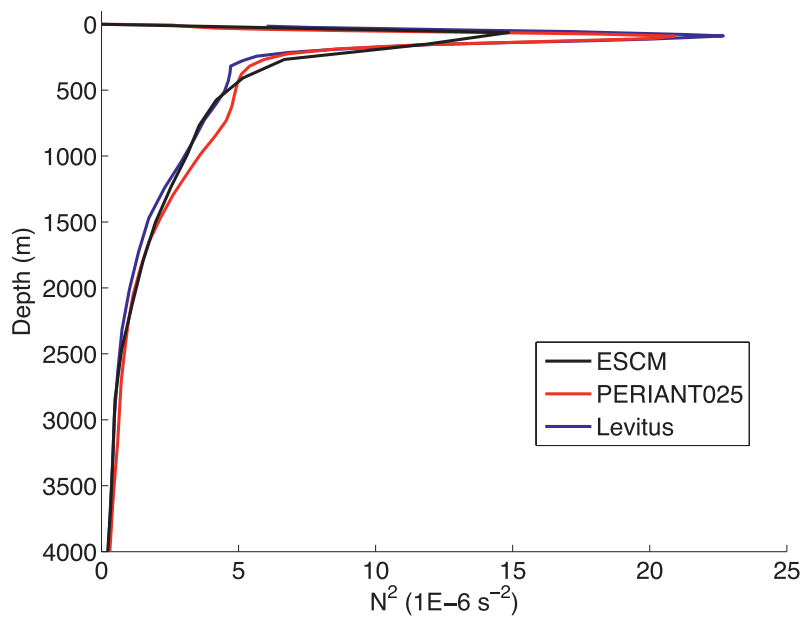

FIG. 4. Profile of the annual-mean buoyancy frequency squared, $N^{2}=-\left(g / \rho_{o}\right) \partial_{z} \sigma_{2}$, where $g$ is the gravitational acceleration, $\rho_{o}$ is a seawater reference density, and $\sigma_{2}$ is the seawater specific potential density referenced to $2000-\mathrm{m}$ depth. The profiles are averaged in the SO between $60^{\circ}$ and $50^{\circ} \mathrm{S}$. The $N^{2}$ profiles as simulated by the ESCM and PERIANT025 are shown, along with that derived from the observational atlases of Levitus (Locarnini et al. 2010; Antonov et al. 2010).

by the models (i.e., those with $L \sim R$ ) are not a major component of SO eddy heat transport, at least in the way it is defined by Volkov et al. (2010).

While eddy-permitting models, such as those employed here, are expected to underestimate EKE, they may still capture a good portion of the observed eddy heat transport if they simulate the eddy-induced streamfunction $\Psi^{*}$ and ocean stratification reasonably well. This follows since $\Psi^{*}$ can be defined as $\Psi^{*}=\left(\overline{v^{\prime} b^{\prime}}\right) / \partial_{z} \bar{b}$ (e.g., Karsten and Marshall 2002), so that the meridional eddy buoyancy transport is $\overline{v^{\prime} b^{\prime}}=\Psi^{*} N^{2}$, with $b$ and $N$ being buoyancy and mean buoyancy frequency, respectively. Figure 4 shows the profiles of $N^{2}$ in the Southern Ocean averaged between $60^{\circ}$ and $50^{\circ} \mathrm{S}$ as simulated by the ESCM and PERIANT025 along with that derived from the observational atlases of Levitus (Locarnini et al. 2010; Antonov et al. 2010). The models are shown to capture the mean observed stratification in the Southern Ocean reasonably well. The PERIANT025 simulation compares more favorably to the observed values near the surface than the ESCM simulation, since PERIANT025 is constrained by observationally based surface fluxes and has a more refined vertical resolution than the ESCM.

Unfortunately, $\left|\Psi^{*}\right|$ remains a difficult quantity to derive from observations. Using the $\mathrm{SSH}$ data from Ocean Topography Experiment (TOPEX)/Poseidon and Levitus climatology, Karsten and Marshall (2002) estimated the maximum $\left|\Psi^{*}\right|$ transport to be about $30 \mathrm{~Sv}$. This value is larger than ESCM's value of maximum $\left|\Psi^{*}\right|$ 

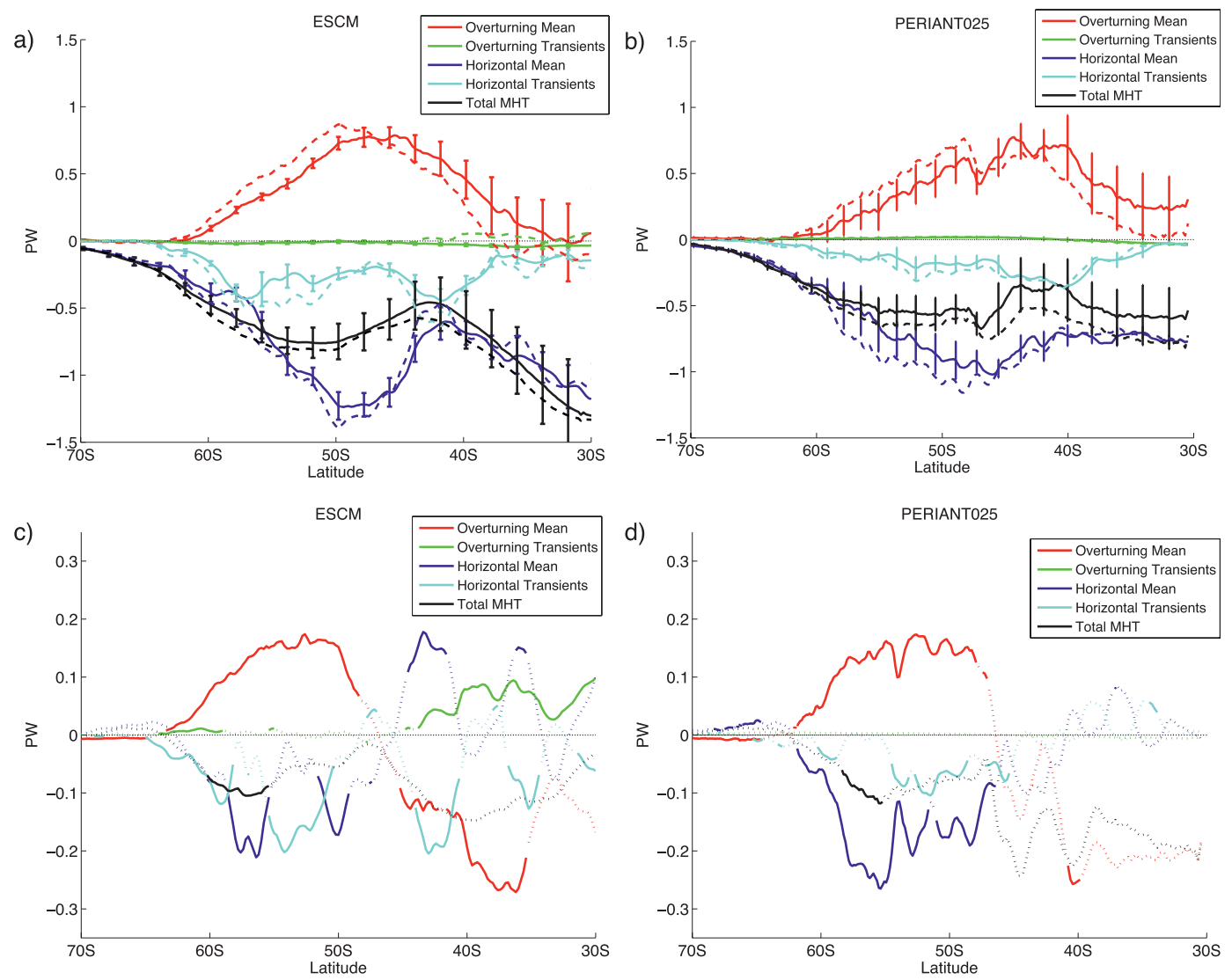

FIG. 5. (a),(b) Solid lines show the SO total MHT in the ESCM_CNTRL and PER_CNTRL runs and that due to the time-mean meridional overturning, the transients in the overturning, the time-mean horizontal circulation, and the transients in the horizontal circulation. Error bars indicate the one standard deviation range of interannual variability of each component. Dashed lines show the summation of the anomaly in response to projected wind stress changes (averaged over the last $5 \mathrm{yr}$ of the forcing runs) with the control state MHT of each component. (c),(d) The total MHT anomaly and its components (averaged over the last $5 \mathrm{yr}$ of the forcing runs) in response to the project changes in the wind stress. Solid (dashed) lines present latitudes where the anomaly is greater (less) than a 1.5 standard deviation range of interannual variability. Note that the PERIANT025 model configuration domain ends at $30^{\circ} \mathrm{S}$.

of about $\sim 16 \mathrm{~Sv}$ (see Saenko et al. 2012) and the $\sim 13 \mathrm{~Sv}$ found in PERIANT025 (see Dufour et al. 2012). It is also larger than the $\sim 20 \mathrm{~Sv}$ arrived at by Treguier et al. (2007). We note that the lower boundary of the eddyinduced streamfunction estimate of Karsten and Marshall (2002) is between 20 and $25 \mathrm{~Sv}$ : that is, closer to the model estimates presented here. Furthermore, while one may expect the eddy MHT to increase with increasing resolution at the expense of the MHT by the mean flow, the enhanced eddy heat transport could be compensated by greater ocean heat loss at the surface.

\section{Results}

\section{a. Southern Ocean MHT in the control simulations}

The estimates of the MHT components in the ESCM CNTRL and PER_CNTRL runs are presented by the solid lines in Figs. 5a,b, with the error bars indicating the one standard deviation range of interannual variability. The overall magnitude and latitudinal dependence of MHT components in the simulations are similar to the corresponding estimates in Volkov et al. (2010) (see their Fig. 5), which are derived from an eddy-permitting global ocean simulation constrained by in situ and satellite observations. In particular, the northward MHT due to the time-mean meridional overturning circulation (MOC) is positive, with a maximum of about $0.75 \mathrm{PW}$ around $45^{\circ} \mathrm{S}$ in ESCM_CNTRL, PER_CNTRL, and Volkov et al. (2010). The contribution of the transient overturning to the net MHT is small. The net MHT is southward at all latitudes, which is largely due to the time-mean horizontal circulation. The transient processes in the horizontal circulation transport heat southward at all SO latitudes.

The net southward MHT equatorward of roughly $35^{\circ} \mathrm{S}$ in ESCM_CNTRL is large relative to PER_CNTRL and Volkov et al. (2010). This difference is attributed to a 
relatively weak northward time-mean overturning transport and strong southward time-mean horizontal transport in ESCM_CNTRL. We note that surface buoyancy fluxes are unconstrained by observations in the ESCM. The local maximum in the ESCM_CNTRL time-mean horizontal heat transport between $45^{\circ}$ and $50^{\circ} \mathrm{S}$ is larger (by a factor of 1.5) than that obtained by Volkov et al. (2010). Between $55^{\circ}$ and $60^{\circ} \mathrm{S}$ and between $40^{\circ}$ and $45^{\circ} \mathrm{S}$, the magnitude of the ESCM_CNTRL eddy heat transport is comparable to that due to the time-mean horizontal circulation (Fig. 5), which is consistent with Volkov et al. (2010), while the PER_CNTRL eddy heat transport is weak relative to the mean horizontal transport at all latitudes.

\section{b. Southern Ocean MHT response to projected wind stress}

In response to the projected changes in wind stress, the net SO MHT increases southward in both models (Fig. 5), but the change is insignificant relative to a 1.5 standard deviation range of interannual variability at most SO latitudes, except between $55^{\circ}$ and $62^{\circ} \mathrm{S}$. However, changes exceeding the internal variability estimate are found for individual MHT components at most latitudes south of $30^{\circ} \mathrm{S}$ for ESCM_SAM and south of $45^{\circ} \mathrm{S}$ for PER_SAM (Figs. 5c,d). The significant changes (with respect to 1.5 standard deviation of interannual variability) in MHT components tend to compensate each other, with little overall impact on the net MHT. In particular, between $45^{\circ}$ and $55^{\circ} \mathrm{S}$ there are significant changes in the transient horizontal, mean horizontal, and mean overturning heat transports of both models, but the change in the total MHT is not significant. The same applies between $30^{\circ}$ and $45^{\circ} \mathrm{S}$ for the ESCM_SAM, where the MHT change due to the mean overturning, mean horizontal, and transient horizontal circulations are all significant but the change in the total MHT is not. The MHT response in PER_SAM is generally not significant south of $45^{\circ} \mathrm{S}$. Control state forcings applied at the $30^{\circ} \mathrm{S}$ northern boundary in PERIANT025 may dampen the low-latitude response.

Note that in both models the compensation is not always between the mean and transient components. In particular, between $50^{\circ}$ and $60^{\circ} \mathrm{S}$ the anomalies due to the transient and the time-mean components of the horizontal circulation are both negative (Figs. 5c,d). However, at $43^{\circ}$ and $38^{\circ} \mathrm{S}$ in ESCM_SAM the horizontal mean and transient components do tend to compensate each other. Prominent SO temperature front positions in this model are found near $43^{\circ} \mathrm{S}$ in the Atlantic Ocean basin and $38^{\circ} \mathrm{S}$ in the Tasman Sea (see Fig. 4 of Spence et al. 2010). A large eddy response can be expected in strong frontal regions, and in the ESCM_SAM simulation the horizontal mean circulation acts to compensate the eddy
MHT anomalies at these latitudes. The MHT anomaly due to the overturning components follows the anomaly in wind stress (Figs. 1, 5), which is to be expected.

The cumulative temperature transport along circles of latitude due to the time-mean horizontal circulation generally supports the notion that warm subtropical waters from the Indian and Pacific basins are carried southward (Volkov et al. 2010). However, both models show this transport to be a complex function of longitude and latitude (Fig. 6, top). For example, abrupt fluctuations at $55^{\circ} \mathrm{S}$ in the mean southward temperature transport occur in the region of the Maquarie Ridge $\left(160^{\circ}\right)$ and near the southern tip of Chile $\left(280^{\circ}\right)$. Topographic steering also causes large fluctuations in this transport at other latitudes (Fig. 6, top), particularly near the Kerguelen Plateau $\left(70^{\circ}\right)$, Southeast Indian Ridge $\left(100^{\circ}\right)$, and Tasman Rise $\left(150^{\circ}\right)$. In contrast, the southward cumulative temperature transport due to the transient processes in the horizontal circulation tends to monotonically increase with a near-constant slope in both models (Fig. 6, bottom). This implies that the eddy heat transport due to meandering of the ACC and eddies is distributed rather uniformly along circles of constant latitude. There are, however, regions common to both models where the slope of the cumulative transient horizontal transport differs substantially from the average value. In particular, a large increase in the southward heat transport tends to occur downstream of the Crozet and Kerguelen Plateaus $\left(50^{\circ}-70^{\circ}\right)$. There are also regions where the eddy meridional heat transport is weak (i.e., the associate cumulative heat transport is near constant) in both models, such as between $200^{\circ}$ and $300^{\circ} \mathrm{E}$ at $45^{\circ} \mathrm{S}$ (Fig. 6 , bottom).

In response to the wind forcing, both models show a net accumulation of southward time-mean horizontal transport at $50^{\circ}$ and $55^{\circ} \mathrm{S}$ and little net change at $45^{\circ} \mathrm{S}$ (Fig. 6, top). The net changes of the MHT due to the time-mean horizontal circulation are small relative to their control state values but are the same order of magnitude as associated change in transient processes (Fig. 6, bottom). The cumulative southward heat transport change due to transient processes in the horizontal circulation tends to increase along $45^{\circ}, 50^{\circ}$, and $55^{\circ} \mathrm{S}$ in PERIANT025 and at $50^{\circ}$ and $55^{\circ} \mathrm{S}$ in the ESCM (Fig. 6, bottom). At $45^{\circ} \mathrm{S}$ in the ESCM, there is a tendency for this transport to decrease between roughly $80^{\circ}$ and $270^{\circ} \mathrm{E}$.

\section{Discussion and conclusions}

Using two high-resolution climate models, we analyze the MHT and its components in the SO. Given the substantial differences in model design, the ESCM and PERIANT025 simulations provide a coherent picture 
a)

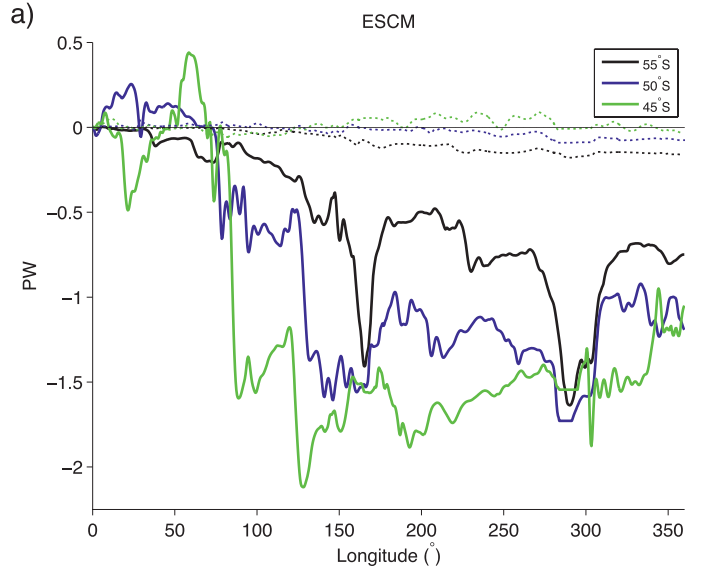

c)

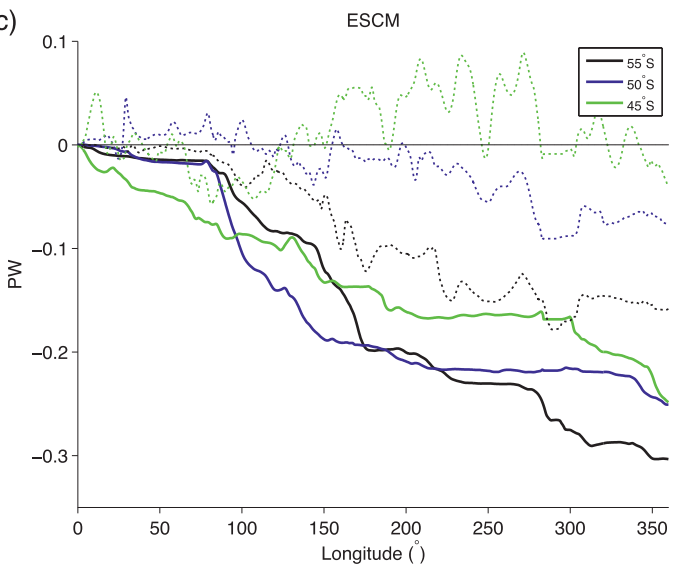

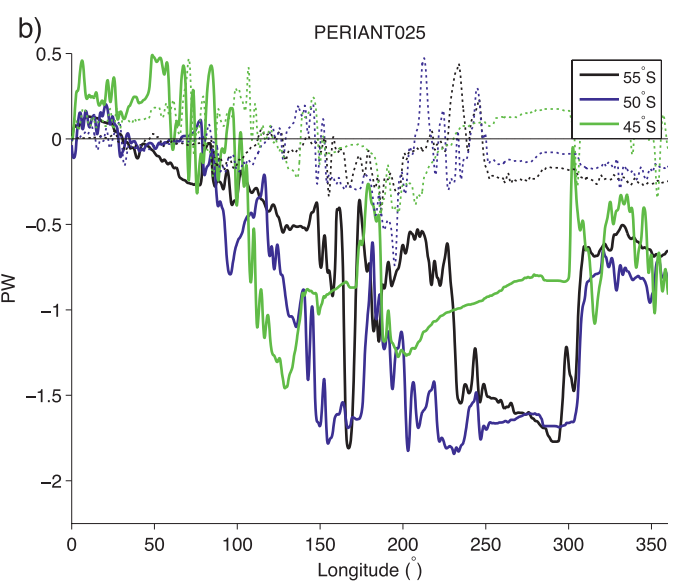

d)

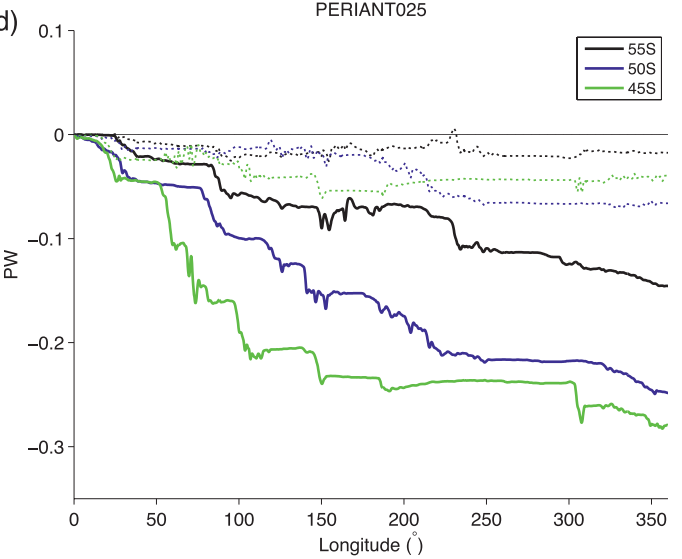

FIG. 6. Zonal cumulative depth-integrated temperature transports at three latitudes in the (left) ESCM and (right) PERIANT025 simulations due to (top) the time-mean horizontal circulation and (bottom) transient processes in the horizontal circulation. Solid lines are for the control state simulations and dashed lines are anomalies averaged over the last $5 \mathrm{yr}$ of the SAM forcing simulations.

of the mechanisms of MHT in the SO, particularly south of $45^{\circ} \mathrm{S}$. In agreement with a recent analysis based on an ocean data synthesis product, much of the MHT in both models is shown to be due to the time-mean fields of meridional velocity and temperature rather than due to the mesoscale eddy field (the latter is expected to dominate the cross-stream heat transport). The net southward MHT in the SO is largely due to the timemean horizontal circulation, with a sizeable contribution from the associated transient processes. The MHT due to the time-mean overturning is also large and directed northward, whereas the heat transport due to transient overturning processes is relatively small. Note that, while the transient MHT of the two eddy-permitting models compares well with an ocean data synthesis product, heat fluxes at smaller scales, particularly the contribution by lateral diffusion, remain unquantified.

The models also present a consistent picture of the SO MHT response to the projected end of the twenty-firstcentury changes in SO wind stress. In particular, in both models the net change in the MHT is within the 1.5 standard deviation range of interannual variability at most latitudes. However, significant changes that tend to compensate each other are consistently found south of $30^{\circ} \mathrm{S}$ in separate components of the MHT. A simple framework wherein changes in the eddy and mean heat transports tend to compensate each other is not supported by our results. Instead, the MHT response is composed of sizeable contributions from essentially all of the MHT components, with the eddy and mean heat transports often having the same sign. The tendency for different components of the MHT to compensate each other in response to changing winds implies that focusing on an individual MHT component (e.g., the transient eddy fluxes) may be somewhat misleading.

Along circles of latitude, the cumulative temperature transports due to the time-mean horizontal circulation are highly nonuniform. The large fluctuations in this transport can be attributed to steering by large-scale topographic features. In contrast, the corresponding 
temperature transports due to transient processes tend to be more monotonic functions of longitude. In response to the changes in the wind stress, these eddy heat transports increase in most parts of the SO. The MHT change due to the time-mean horizontal circulation is of comparable magnitude to the change in the associated transient processes in both models. These results may shed some light on the mechanisms that drive temperature changes in the Southern Ocean associated with the projected changes in westerly winds.

Acknowledgments. We are grateful for the computing support of Andrew Weaver and the University of Victoria Climate Lab. We also thank J. Fyfe for supplying the projected wind anomalies. Infrastructure support from the University of New South Wales is acknowledged. Support from the Australian Research Council Centre of Excellence for Climate System Science is acknowledged.

Partial support from the Agence Nationale de la Recherche through Contract ANR-08-JCJC-0777-01 is acknowledged. PERIANT025 simulations have been produced within the Drakkar consortium, which is supported by GMMC, CNES, and CNRS. PERIANT025 simulations were carried out at the CNRS IDRIS super computer facility in Orsay, France, and at the CINES super computer facility in Montpellier, France.

\section{REFERENCES}

Antonov, J. I., and Coauthors, 2010: Salinity. Vol. 2, World Ocean Atlas 2009, NOAA Atlas NESDIS 69, 184 pp.

Barnier, B., and Coauthors, 2006: Impact of partial steps and momentum advection schemes in a global ocean circulation model at eddy permitting resolution. Ocean Dyn., 56 (5-6), 543-567.

Brodeau, L., B. Barnier, T. Penduff, A. Treguier, S. Gulev, and T. McDougall, 2010: An ERA-40 based atmospheric forcing for global ocean circulation models. Ocean Modell., 31, 88-104.

Bryan, K., 1982: Poleward heat transport by the ocean: Observations and models. Annu. Rev. Earth Planet. Sci., 10, 15-38.

de Szoeke, R. A., and M. D. Levine, 1981: The advective flux of heat by mean geostrophic motions in the Southern Oceans. Deep-Sea Res., 28, 1057-1085.

Drakkar Group, 2007: Eddy-permitting ocean circulation hindcasts of past decades. CLIVAR Exchanges, No. 42, International CLIVAR Project Office, Southampton, United Kingdom, 8-10.

Ducet, N., P. Y. Le Traon, and G. Reverdin, 2000: Global highresolution mapping of ocean circulation from TOPEX/Poseidon and ERS-1 and -2. J. Geophys. Res., 105 (C8), 19 477-19 498.

Dufour, C. O., J. Le Sommer, J. D. Zika, M. Gehlen, J. C. Orr, P. Mathiot, and B. Barnier, 2012: Standing and transient eddies in the response of the Southern Ocean meridional overturning to the southern annular mode. J. Climate, 25, 6958-6974.

Farneti, R., and T. L. Delworth, 2010: The role of mesoscale eddies in the remote oceanic response to altered Southern Hemisphere winds. J. Phys. Oceanogr., 40, 2348-2354.
Fasullo, J. T., and K. E. Trenberth, 2008: The annual cycle of the energy budget. Part II: Meridional structures and poleward transports. J. Climate, 21, 2313-2325.

Fyfe, J. C., O. A. Saenko, K. Zickfeld, M. Eby, and A. J. Weaver, 2007: The role of poleward intensifying winds on Southern Ocean warming. J. Climate, 20, 5391-5400.

Ganachaud, A., and C. Wunsch, 2003: Large-scale ocean heat and freshwater transports during the World Ocean Circulation Experiment. J. Climate, 16, 696-705.

Gill, A. E., 1982: Atmosphere-Ocean Dynamics. Academic Press, $662 \mathrm{pp}$.

Gille, S., 2003: Float observations of the Southern Ocean. Part II: Eddy fluxes. J. Phys. Oceanogr., 33, 1182-1196.

Hogg, A., M. Meredith, J. Blundell, and C. Wilson, 2008: Eddy heat flux in the Southern Ocean: Response to variable wind forcing. J. Climate, 21, 608-620.

Jayne, S. R., and J. Marotzke, 2002: The oceanic eddy heat transport. J. Phys. Oceanogr., 32, 3328-3345.

Karsten, R. H., and J. Marshall, 2002: Constructing the residual circulation of the ACC from observations. J. Phys. Oceanogr., 32, 3315-3327.

Kistler, R., and Coauthors, 2001: The NCEP-NCAR 50-Year Reanalysis: Monthly means CD-ROM and documentation. Bull. Amer. Meteor. Soc., 82, 247-267.

Locarnini, R. A., A. V. Mishonov, J. I. Antonov, T. P. Boyer, H. E. Garcia, O. K. Baranova, M. M. Zweng, and D. R. Johnson, 2010: Temperature. Vol. 1, World Ocean Atlas 2009, NOAA Atlas NESDIS 68, 184 pp.

Madec, G., 2008: NEMO ocean engine. Institut Pierre-Simon Laplace Note du Pole de Modelisation 27, 1288-1619.

Mazloff, M., P. Heimbach, and C. Wunsch, 2010: An eddypermitting Southern Ocean state estimate. J. Phys. Oceanogr., 40, 880-899.

Meijers, A., N. Bindoff, and J. Roberts, 2007: On the total, mean, and eddy heat and freshwater transports in the Southern Hemisphere of a $1 / 8^{\circ} \times 1 / 8^{\circ}$ global ocean model. J. Phys. Oceanogr., 37, 277-295.

Pacanowski, R., 1995: MOM 2 documentation users guide and reference manual. GFDL Ocean Group Tech. Rep., 232 pp.

Saenko, O. A., 2009: On the climatic impact of wind stress. J. Phys. Oceanogr., 39, 207-214.

— A. Sen Gupta, and P. Spence, 2012: On challenges in predicting bottom water transport in the Southern Ocean. J. Climate, 25, 1349-1356.

Spence, P., J. C. Fyfe, A. Montenegro, and A. J. Weaver, 2010: Southern Ocean response to strengthening winds in an eddypermitting global climate model. J. Climate, 23, 5332-5343.

Stammer, D., 1997: Global characteristics of ocean variability estimated from regional TOPEX/POSEIDON altimeter measurements. J. Phys. Oceanogr., 28, 1743-1769.

Treguier, A. M., M. H. England, S. R. Rintoul, G. Madec, J. Le Sommer, and J. M. Molines, 2007: Southern Ocean overturning across streamlines in an eddying simulation of the Antarctic Circumpolar Current. Ocean Sci., 3, 491-507.

Trenberth, K., and J. Caron, 2001: Estimates of meridional ocean and atmosphere heat transport. J. Climate, 14, 3433-3443.

Uppala, S., and Coauthors, 2005: The ERA-40 Re-Analysis. Quart. J. Roy. Meteor. Soc., 131, 2961-3012.

Volkov, D. L., L.-L. Fu, and T. Lee, 2010: Mechanisms of the meridional heat transport in the Southern Ocean. Ocean Dyn., 60, 791-801.

Weaver, A. J., and Coauthors, 2001: The UVic Earth System Climate Model: Model description, climatology and application to past, present and future climates. Atmos.-Ocean, 39, 361-428. 